\title{
LICENCIATURA NO CURSO DE PSICOLOGIA: PANORAMA NO SÉCULO XXI
}

\author{
TEACHER TRAINING COURSES IN THE PSYCHOLOGY: \\ OVERVIEW IN THE 21 ${ }^{\text {st }}$ CENTURY
}

\author{
Diego Ranielly Dias Silva ${ }^{1}$ \\ Kesley de Jesus Leal ${ }^{2}$ \\ Leonardo Augusto Couto Finelli ${ }^{3}$
}

\begin{abstract}
RESUMO
O processo de hominização leva ao desenvolvimento do indivíduo no mundo. Percebe-se que a aliança entre a Psicologia e a Educação promove o desenvolvimento da sociedade ao ampliar esse processo. Desde seu reconhecimento enquanto profissão, no Brasil, em 1962, a Psicologia já assumia a perspectiva da formação para modalidade da Licenciatura, porém com as mudanças nas políticas educacionais, essa foi sendo esquecida. Não obstante, a partir da LDB de 1996, há a retomada de tal modalidade educacional que passa a ganhar força no avançar do século XXI. Nesse sentido, o presente artigo retoma a evolução da legislação das diretrizes curriculares de graduação de Psicologia que tratam da Licenciatura no curso de Psicologia. A partir da discussão documental, realizou-se o levantamento das IES que oferecem a opção de ênfase em licenciatura. Tais dados foram buscados a partir dos respectivos cadastros de oferta de curso no e-MEC, e desse da matriz de cada instituição. Como resultados verificou-se que 543 IES oferecem a graduação em psicologia, dessas, conseguiu-se analisar as matrizes de 470 instituições. Dessas, verificou-se que 425 instituições não oferecem a Licenciatura em Psicologia em sua matriz curricular. As 45 que ofertam levam a discussão sobre quais as dificuldades e empecilhos para tal implementação, assim como a consideração da perda associada para a formação dos profissionais da Psicologia, assim como para o desenvolvimento da sociedade em geral, que não tem a oferta de tais discussões na formação de alunos da educação nos mais diversos níveis e modalidades de ensino.
\end{abstract}

Palavras-chave: Licenciatura em Psicologia. História da Psicologia. LDB. DCN. Ensino Superior.

\section{ABSTRACT}

The hominization process leads to the development of the individual in the world. It is clear that the alliance between Psychology and Education promotes the development of society by expanding this process. Since its recognition as a profession, in Brazil, in 1962, Psychology has already taken the perspective of education for the modality of teacher training courses, however with the changes in educational policies, this has been forgotten. Nevertheless, since the LDB, of 1996, there is a resumption of such an educational modality that gains strength in the 21 st century progresses. In this sense, this article takes up the evolution of the legislation of the Psychology undergraduate curriculum guidelines that deal with the teacher training courses in the Psychology. Based on the documentary discussion, a survey was carried out of the HEIs that offer the option of this emphasis to the degree. Such data were sought from the respective registers of HEIs at eMEC, and from the matrix of each institution As result, it was found that 543 HEIs offer degrees in psychology, of these, it was possible to analyze the matrices of 470 institutions. Of these, it was found that 425 institutions do not offer the teacher training courses in Psychology curriculum. The 45 which offer may help to think in the discussion about what are the difficulties and obstacles to such implementation, as well as the consideration of the associated loss for the training of Psychology professionals, as well as for the development of society in general, which does not have the offer of such discussions in the training of education students at the most diverse levels of teaching and teaching modalities.

Keywords: Teacher Training Courses in Psychology. History of Psychology. LDB. DCN. University education.

${ }^{1}$ Psicólogo (FASI). E-mail: diego.ranielly.13@ gmail.com.br, ORCID: https://orcid.org/0000-0001-9224-2709. 2Psicóloga (FASI). E-mail::kesley.kika@ gmail.com, ORCID: https://orcid.org/0000-0001-5364-9653.

${ }^{3}$ Doutor em Ciências da Educação (UEP), Mestre em Psicologia (USF), Graduado em Psicologia (UFMG), Graduado em Pedagogia (FETAC), Professor adjunto das Faculdades Integradas do Norte de Minas - FUNORTE. E-mail: finellipsi@gmail.com,_ORCID:_https://orcid.org/0000-0001-6108-7611. 


\section{Introdução}

O presente trabalho se dispõe a realizar o levantamento da situação da proposição de inclusão da ênfase de formação em Licenciatura nas matrizes curriculares dos cursos de graduação em Psicologia no Brasil. Isso porque quando foi promulgada a Resolução CNE/CES $n^{\circ}$ 5, de 15 de março de 2011 do Conselho Nacional de Educação - CNE (BRASIL, 2011), houve a determinação de que haja complementação na formação de Psicólogos para a atuação nas “políticas públicas de educação, na educação básica, no nível médio, no curso Normal, em cursos profissionalizantes e em cursos técnicos, na educação continuada, assim como em contextos de educação informal como abrigos, centros socioeducativos, instituições comunitárias e outros". Tal ajustamento, na formação, considera, entre outros elementos, a previsão desse profissional agir com o ensino de Psicologia nas escolas e demais instituições de ensino, em seus diversos níveis.

Antes de avançar, objetivamente, para tal discussão, ter-se-á de falar sobre o que de fato é a Psicologia. Para essa explanação considera-se: ao que a mesma se propõe; como se dá sua formação/graduação; e, seus impactos para a educação, a fim de compreender o objetivo do trabalho.

A Psicologia surge, a priori, a partir "ideias psicológicas" discutidas entre os filósofos da Antiga Grécia que se debruçaram sobre o pensamento a respeito do ser humano. As questões fundantes, como: 'Quem eu sou?'; ‘De onde vim?'; 'Para onde vou?'; 'Como me relacionar com meus pares?'; 'Ou com o mundo?’ determinaram esse início. Com o passar dos anos ao se chegar à era do Iluminismo (entre 1715 e 1789), onde "tudo era explicado", só se aceitavam explicações científicas sobre os diversos fenômenos. A partir de tal período a Psicologia passou a ser pensada também como tema científico (BOCK, TEIXEIRA, FURTADO, 2001).

No final do século XIX, a Psicologia surge com status de ciência, inicialmente na Europa e em seguida nos Estados Unidos. Seu reconhecimento como ciência formal se dá com a fundação do primeiro laboratório de psicologia, em Leipzig, na Alemanha, pelo psicólogo alemão Wilhelm Maximillian Wundt, em 1879. Nesse, Wundt inicia a história da Psicologia a partir do prisma da Avaliação Psicológica. Para tal propôs métodos positivistas e empíricos para mensurar habilidades sensoriais, as quais associou ao funcionamento psíquico do indivíduo, e assim, passou a predizer comportamentos e intenções futuras de tais sujeitos. A partir daí a Psicologia toma força, e os experimentos propostos por Wundt são replicados e ampliados por outros pesquisadores (JACÓ-VILELA et al., 2016). 
Com o início do século XX, a ciência emergente seguiu seu desenvolvimento no campo da teoria, da pesquisa, e, da prática. Para tal, perfez seu potencial de aplicação técnica (SILVA JUNIOR; CATARINI; PRUDENTE, 2006). A partir do início da Segunda Guerra Mundial, foi amplamente utilizada, em especial, na forma da Avaliação Psicológica, como ferramenta para seleção dos soldados, assim como de acompanhamento de soldados traumatizados pós-guerra, em sua perspectiva de atendimento clínico. Assim, seus impactos e atuação passaram a ser mais conhecidos e divulgados nas diversas sociedades e culturas (SCHULTZ; SCHULTZ, 2005).

Quando se pensa sobre o objeto de estudo da Psicologia, de forma ampla, tem-se o ser humano como um todo. Em termos de técnicas e/ou compreensão epistemológica, a Psicologia se divide em várias abordagens, entre elas o Behaviorismo, que foca analisar o comportamento humano; a Psicanálise, que tem como principal objeto de estudo o inconsciente; a Gestalt, que leva em conta a forma de "ver o mundo" do indivíduo; a Teoria Cognitiva Comportamental, que leva em consideração para seu trabalho a cognição e sua implicação no comportamento; a Sistêmica que tem um olhar do sujeito inserido nos seus sistemas sociais (família, comunidade); o Humanismo, que leva em conta as potencialidades do sujeito; entre outras (BOCK, TEIXEIRA, FURTADO, 2001).

Para além de tal diversidade de abordagens epistemológicas deve-se reconhecer ainda que a Psicologia é útil para a atuação em diversas áreas ou campos. Diferente da ideia popular que reconhece a clínica individual como o campo de trabalho, por excelência, do psicólogo; a Psicologia também se dispõe a trabalhar na área social; com a assistência social; no âmbito educacional; da saúde mental; na área organizacional; com saúde e trabalho; gestão de pessoas; RH (recursos humanos); recrutamento e seleção; bem como tantos outros campos que o saber psicológico abrange (FINELLI; FREITAS; CAVALCANTI, 2015).

A busca por uma formação adequada faz-se necessária frente aos desafios da profissão reconhecida no Brasil. Esse reconhecimento se deu a partir da Lei n ${ }^{\circ} 4.119$ de 27 de agosto de 1962 (BRASIL, 1962), que regulamenta tanto a questão da formação em Psicologia quanto o exercício da profissão. Essa mesma lei cita que o profissional formado como Bacharel em Psicologia, poderá ministrar cursos no ensino médio de acordo com as legislações vigentes; o profissional coma formação em Licenciatura em Psicologia poderá lecionar psicologia, atendidas as exigências legais devidas; e, com o diploma de psicólogo é conferido o direito de ensinar Psicologia nos vários cursos de que trata a referida lei (FINELLI, 2013).

A partir de tal regulamentação estabeleceram-se os padrões de ética e de conduta do profissional Psicólogo. De 1962 em diante, foram estabelecidas modificações, em âmbito 
legislativo, que deram origem a uma série de discussões significativas para a regulamentação da profissão. Essas contemplavam, principalmente, o estabelecimento de um currículo do curso; as disciplinas e técnicas lecionadas; as características da formação básica e especializada; bem como a relação entre a formação e o exercício profissional (ROSA, 2018).

Considerados os aspectos da formação superior no Brasil, a Lei no 4.119/62 (BRASIL, 1962) já sistematizava a formação do Psicólogo. Porém, com os avanços da história, a educação também evolui. Foi promulgada a Lei de Diretrizes e Bases da Educação Nacional - LDB, nos dispositivos da Lei $n^{\circ}$ 9394, de 20 de dezembro de 1996 (BRASIL, 1996), e com essa, modificaram-se, radicalmente, os parâmetros para se pensar a educação no Brasil. A partir de 1997, com o Parecer CNE/CES n ${ }^{\circ} 776 / 1997$, começam a serem pensados os parâmetros das Diretrizes Curriculares Nacionais - DCN para os Cursos de Graduação (BRASIL, 1997a), e desses diversos documentos oficiais são criados para regulamentar a formação nos Cursos de Graduação.

Especificamente, a primeira DCN para o curso de graduação em Psicologia (BRASIL, 2004), figurava, entre outros elementos, que:

\begin{abstract}
Art. $13^{\circ}$ - A formação do professor de Psicologia dar-se-á em um projeto pedagógico complementar e diferenciado, elaborado em conformidade com a legislação que regulamenta a formação de professores no país.

Parágrafo $1^{\circ}$. O projeto pedagógico para a formação do Professor de Psicologia deve propiciar o desenvolvimento das competências e habilidades básicas constantes no núcleo comum do curso de Psicologia e daquelas previstas nas Diretrizes Nacionais para a formação do professor da Educação Básica, em nível superior.

Art. 14 - A organização do curso de Psicologia deve, de forma articulada, garantir o desenvolvimento das competências do núcleo comum, seguido das competências das partes diversificadas - ênfases - sem concebê-los, entretanto, como momentos estanques do processo de formação.
\end{abstract}

Observe-se que, quanto à formação, a DCN considera a "conformidade com a legislação que regulamenta a formação", e, em especial, o parágrafo $1^{\circ}$ do artigo $13^{\circ}$ já entende que a formação do Professor de Psicologia deve atender as "competências e habilidades básicas constantes no núcleo comum" acrescidas das "previstas nas Diretrizes Nacionais" e o destaque que se apresenta para a "formação do professor da Educação Básica, em nível superior" (BRASIL, 2004).

Mas essa legislação também não ficou como uma organização estática. Ao considerar como a formação se dá, e suas demandas, a DCN foi acrescida de documentações complementares. Com essas assomando-se, houve a proposição de nova DCN, como previsto no Parecer CNE/CES no 338/2009 (BRASIL, 2009), que, por sua vez, levou a atual DCN que está 
disposta na Resolução CNE/CES n 5, de 15 de março de 2011, que instituiu as DCN para os cursos de graduação em Psicologia em vigor (BRASIL, 2011).

Tal reconhece o movimento da formação para a Licenciatura em Psicologia, que foi sendo esquecido desde o reconhecimento da Psicologia em 1962. Para isso, entende que há que se estabelecer normas para o projeto pedagógico complementar para a Formação de Professores de Psicologia. Assim, a Resolução N 5, de 15 de março de 2011 (BRASIL, 2011), resolve:

Art. $1^{\circ}$ A presente Resolução institui as Diretrizes Curriculares Nacionais para os cursos de graduação em Psicologia, a serem observadas pelas Instituições de Ensino Superior do País.

Art. $2^{\circ}$ As Diretrizes Curriculares para os cursos de graduação em Psicologia constituem as orientações sobre princípios, fundamentos, condições de oferecimento e procedimentos para o planejamento, a implementação e a avaliação deste curso.

Art. $3^{\circ} \mathrm{O}$ curso de graduação em Psicologia tem como meta central a formação do psicólogo voltado para a atuação profissional, para a pesquisa e para o ensino de Psicologia, e deve assegurar uma formação baseada nos seguintes princípios e compromissos:

I - Construção e desenvolvimento do conhecimento científico em Psicologia;

II - Compreensão dos múltiplos referenciais que buscam apreender a amplitude do fenômeno psicológico em suas interfaces com os fenômenos biológicos e sociais;

III - Reconhecimento da diversidade de perspectivas necessárias para compreensão do ser humano e incentivo à interlocução com campos de conhecimento que permitam a apreensão da complexidade e multideterminação do fenômeno psicológico;

IV - Compreensão crítica dos fenômenos sociais, econômicos, culturais e políticos do País, fundamentais ao exercício da cidadania e da profissão;

V - Atuação em diferentes contextos, considerando as necessidades sociais e os direitos humanos, tendo em vista a promoção da qualidade de vida dos indivíduos, grupos, organizações e comunidades;

VI - Respeito à ética nas relações com clientes e usuários, com colegas, com o público e na produção e divulgação de pesquisas, trabalhos e informações da área da Psicologia;

VII - Aprimoramento e capacitação contínuos.

Nesse sentido, reconhece a urgência nas modificações no processo ensinoaprendizagem que era largamente discutida pelos diversos segmentos da educação. Essas modificações incluem o olhar da Psicologia sobre as demandas apresentadas pelos novos alunos, que têm expectativas sobre questões de formação que são vivenciadas no âmbito escolar, social, e, familiar. Diante disso, a legislação federal, na forma da LDB (BRASIL, 1996), das DCNs (BRASIL, 1997a), e, dos Parâmetros Curriculares Nacionais - PCNs (BRASIL, 1997b), já indicavam a necessidade de um ensino contextualizado e interdisciplinar que visasse à melhoria continua dos alunos (de todos os níveis de formação) diante dos obstáculos encontrados na relação entre a escola e a aprendizagem (OLIVEIRA et al., 2018).

O Plano Nacional de Educação em Direitos Humanos - PNEDH, discutido entre 2003 e 2005, e, implantado em 2006 pelo Ministério de Educação e Cultura - MEC, já considerava a 
instituição escolar como um espaço que conduz a promoção da cidadania, ao promover o desenvolvimento do sujeito para além do mercado de trabalho (CNEDH, 2018). Os estudantes dos mais diversos sistemas e níveis de ensino devem ser integrandos na sociedade de forma concreta para a formação de cidadãos de bem. Dessa forma, a Psicologia, pautada em uma escuta e olhar diferenciados, além estudar os processos psíquicos e de comportamentos, por intermédio de suas relações com as emoções, valores, crenças, e, subjetividade, conduz o acadêmico a entender que a aprendizagem vai além de estudar conteúdos formais como português e matemática (e todos os demais elencados na matriz curricular e Projeto Político Pedagógico da escola). Assim, conteúdos formais das disciplinas de Psicologia promovem o desenvolvimento do aluno para sua formação para a vida (GUIMARÃES, 2016).

Tal percepção corrobora a ideia de que "À educação se identifica com o processo de hominização. A educação é o que se pode fazer do homem de amanhã” (GADOTTI, 1983, p. 149). Nesse sentido, reconhece-se que a sociedade se faz diante da realização do homem inserido nesta sociedade.

Assim, a aprendizagem surge como um aprimoramento de habilidades que são desenvolvidas decorrentes do espaço escolar. Além disso, a escola promove a emergência de uma relação social entre seus membros, assim como desses com a sociedade. Tais relações são compactuadas naquele espaço social, onde se criam relações emocionais (FERNANDEZ, 1991).

Entende-se então que, a fim de contribuir com a aprendizagem, fez-se necessário como método para a prática pedagógica, a adoção de conteúdos relacionados à disciplina formal de Psicologia como de interesse educacional. Entende-se que tal conteúdo traz grandes contribuições a formação da criança e do adolescente, assim como permitirá a emergência de uma nova perspectiva na estrutura curricular de alunos nos ensinos fundamental e médio. Estabelece-se assim uma visão voltada para mediação com uma adoção de métodos inovadores de ensino, que permitem uma prática pedagógica crítica, transformadora, e reflexiva, que permitirá a criação de um novo ser humano (MITRE et al., 2008).

Nessa perspectiva, ao se assumir a disciplina de Psicologia com conteúdo voltado para a formação em ensinos fundamental e médio, faz-se necessário à capacitação de professores para o ministério das mesmas. Assim, retoma-se a perspectiva da formação da Licenciatura em Psicologia, onde serão capacitados professores para a docência nos ensinos fundamental e médio (nas mais diversas modalidades, mas excluindo-se o ensino superior) com as competências adequadas para tal regência.

A formação da Licenciatura em Psicologia oferece um conjunto de conhecimentos 
complementares que ampliam a formação em nível de Bacharelado e/ou Psicólogo. Essa deve versar sobre habilidades, atitudes e procedimentos estritamente relacionados à logica da licenciatura e oferecer qualidade quanto aos serviços educacionais prestados (LEITE, 2007; MACHADO; VITÓRIA, 2018). Tal perspectiva é corroborada na nova DCN dos cursos de graduação em Psicologia (BRASIL, 2011)

\section{$O$ retorno da licenciatura em psicologia}

Como mencionado, a possibilidade do estudo de conteúdos de Psicologia voltados para a formação em ensinos fundamental e/ou médio (entre outros) pode ser de grande benefício aos estudantes, que poderiam conhecer mais sobre o ser humano, e assim, ter-se uma sociedade mais humanizada. Entende-se que o disciplina para a formação geral, além de proporcionar um enorme campo de trabalho aos profissionais em psicologia, poderá ser valorizado e reconhecido pela sociedade.

Reconhece-se também a possibilidade de incremento intelectual para a sociedade, já que os PCNs reconhecem que a Psicologia instiga o desenvolvimento do senso crítico sobre os objetos, fatos e fenômenos; além de oferecer ao sujeito um conhecimento sobre si mesmo em relação à sociedade, o que pode ajudar a definição do seu "lugar no mundo" (BRASIL, 1997b).

Nesse sentido, reconhecidas as reformas curriculares para o curso de graduação em Psicologia, retomaram-se as discussões sobre a formação do professor de Psicologia, que já figuravam na forma da Licenciatura em Psicologia, na antiga Lei $\mathrm{n}^{\circ}$ 4.119/1962, mas que, em função das especificidades das políticas educacionais posteriores, entraram em desuso quando a capacitação de novos docentes. Tal discussão começou a ser retomada a partir da LDB de 1996, que considerou novos princípios e fins, assim como nova forma de organização da educação nacional (BRASIL, 1962; 1996).

O caminho para o referido retorno ganhou força com o Projeto de Lei Estadual 237 de 2001, que tornou obrigatória a disciplina de Psicologia no currículo do ensino médio no Estado de São Paulo. O processo continuou com o Projeto de Lei Federal 1.641 de 2003 que acresceu as disciplinas Filosofia e Sociologia nas escolas, que foi operacionalizado a partir da Lei 11.684/08 (MELLO, 2013). Foi ainda complementado pelo Ofício n n 0633-08/DIR-CFP (CFP, 2008), que é documento produzido a partir do encontro de professores do Ensino Médio promovido pelo Conselho Federal de Psicologia - CFP e pela Associação Brasileira de Ensino de Psicologia - ABEP, e versa sobre a disciplina de Psicologia no ensino Médio.

Paralelamente a esse contexto micro, das discussões realizadas no estado de São 
Paulo, em contexto macro, a DCN de 2004, configurou-se como marco, por voltar a legislar sobre a formação do professor de Psicologia. A organização das matrizes para a formação em Licenciatura em Psicologia começou a ser operacionalizada. No entanto até o ano de 2011, de fato, esse processo não se mostrou eficiente (BRASIL, 2004; 2011).

Somente a partir do ano de 2011, com a nova DCN, foi, formalmente, estabelecido o projeto pedagógico complementar para a Formação de Professores de Psicologia (BRASIL, 2011). Essa contempla a formação da Licenciatura em Psicologia nos termos da alteração do artigo $13^{\circ}$ que foi complementado quanto à Formação do Professor de Psicologia, em relação à DCN de 2004 (BRASIL, 2004). Na forma alterada o mesmo é apresentado com a seguinte redação:

Art. 13. A Formação de Professores de Psicologia dar-se-á em um projeto pedagógico complementar e diferenciado, elaborado em conformidade com a legislação que regulamenta a formação de professores no País.

$\S 1^{\circ} \mathrm{O}$ projeto pedagógico complementar para a Formação de Professores de Psicologia tem por objetivos:

a) complementar a formação dos psicólogos, articulando os saberes específicos da área com os conhecimentos didáticos e metodológicos, para atuar na construção de políticas públicas de educação, na educação básica, no nível médio, no curso Normal, em cursos profissionalizantes e em cursos técnicos, na educação continuada, assim como em contextos de educação informal como abrigos, centros socioeducativos, instituições comunitárias e outros;

b) possibilitar a formação de professores de Psicologia comprometidos com as transformações político-sociais, adequando sua prática pedagógica às exigências de uma educação inclusiva;

c) formar professores de Psicologia comprometidos com os valores da solidariedade e da cidadania, capazes de refletir, expressar e construir, de modo crítico e criativo, novos contextos de pensamentos e ação.

$\S 2^{\circ}$ A proposta complementar para a Formação de Professores de Psicologia deve assegurar que o curso articule conhecimentos, habilidades e competências em torno dos seguintes eixos estruturantes:

a) Psicologia, Políticas Públicas e Educacionais, que prepara o formando para compreender a complexidade da realidade educacional do País e fortalece a elaboração de políticas públicas que se articulem com as finalidades da educação inclusiva;

b) Psicologia e Instituições Educacionais, que prepara o formando para a compreensão das dinâmicas e políticas institucionais e para o desenvolvimento de ações coletivas que envolvam os diferentes setores e protagonistas das instituições, em articulação com as demais instâncias sociais, tendo como perspectiva a elaboração de projetos políticopedagógicos autônomos e emancipatórios;

c) Filosofia, Psicologia e Educação, que proporciona ao formando o conhecimento das diferentes abordagens teóricas que caracterizam o saber educacional e pedagógico e as práticas profissionais, articulando-os com os pressupostos filosóficos e conceitos psicológicos subjacentes;

d) Disciplinaridade e interdisciplinaridade, que possibilita ao formando reconhecer o campo específico da Educação e percebê-lo nas possibilidades de interação com a área da Psicologia, assim como com outras áreas do saber, em uma perspectiva de educação continuada. 
$\S 3^{\circ}$ A Formação de Professores de Psicologia deve oferecer conteúdos que:

a) destaquem e promovam uma visão abrangente do papel social do educador, assim como a reflexão sobre sua prática e a necessidade de aperfeiçoamento contínuo do futuro professor;

b) articulem e utilizem conhecimentos, competências e habilidades desenvolvidos no curso de Psicologia para a ampliação e o amadurecimento do papel de professor;

c) considerem as características de aprendizagem e de desenvolvimento dos alunos, o contexto socioeconômico e cultural em que atuarão na organização didática de conteúdos, bem como na escolha das estratégias e técnicas a serem empregadas em sua promoção;

d) promovam o conhecimento da organização escolar, gestão e legislação de ensino referentes à educação no Brasil, assim como a análise das questões educacionais relativas à dinâmica institucional e à organização do trabalho docente;

e) estimulem a reflexão sobre a realidade escolar brasileira e as articulações existentes com as políticas públicas educacionais e o contexto socioeconômico mais amplo.

$\S 4^{\circ}$ Os conteúdos que caracterizam a Formação de Professores de Psicologia deverão ser adquiridos no decorrer do curso de Psicologia e complementados com estágios que possibilitem a prática do ensino.

$\S 5^{\circ}$ A prática profissional do professor-aluno deve se desenvolver em uma perspectiva de análise do trabalho educativo na sua complexidade, cujas atividades devem ser planejadas com a intenção de promover a reflexão e a organização do trabalho em equipes, o enfrentamento de problemas concretos do processo ensino-aprendizagem e da dinâmica própria do espaço escolar, e a reflexão sobre questões ligadas às políticas educacionais do País, aos projetos político-pedagógicos institucionais e às ações político-pedagógicas.

$\S 6^{\circ}$ A carga horária para a Formação de Professores de Psicologia deverá ter, no mínimo, 800 (oitocentas) horas, acrescidas à carga horária do curso de Psicologia, assim distribuídas:

a) Conteúdos específicos da área da Educação: 500 (quinhentas) horas;

b) Estágio Curricular Supervisionado: 300 (trezentas) horas.

$\S 7^{\circ}$ As atividades referentes à Formação de Professores, a serem assimiladas e adquiridas por meio da complementação ao curso de Psicologia, serão oferecidas a todos os alunos dos cursos de graduação em Psicologia, que poderão optar ou não por sua realização.

$\S 8^{\circ}$ Os alunos que cumprirem satisfatoriamente todas as exigências do projeto complementar terão apostilada, em seus diplomas do curso de Psicologia, a licenciatura. (BRASIL, 2011).

Note-se que a alínea 'a' do parágrafo $1^{\circ}$ concebe a Formação de Professores de Psicologia com a articulação dos conhecimentos didáticos e metodológicos para a atuação docente para os diversos níveis do saber. Considera tais conhecimentos para a atuação docente na educação formal, para espaços de ensino não formais, e contextos de educação informal. Concebe ainda a formação para a educação inclusiva, e, a capacidade de preparar cidadãos críticos e criativos para os novos contextos de pensamentos e ação. Especifica ainda que tal profissional esteja preparado para lidar com a gestão e organização escolar, assim como à organização do trabalho docente (BRASIL, 2011).

Destaque também deve ser oferecido aos parágrafos $4^{\circ}$ a $6^{\circ}$ que contemplam a Formação de Professores de Psicologia a partir de estágios de prática do ensino (como considerado em todas as licenciaturas). Tal prática de formação deve lidar com o mínimo de 500 (quinhentas) 
horas de formação que contemplem conteúdos específicos da área da Educação, acrescidas de, no mínimo, 300 (trezentas) horas de formação em Estágio Curricular Supervisionado (BRASIL, 2011).

Reconhece-se então a lógica de que a Formação de Professores de Psicologia entende o Estágio Curricular Supervisionado como a prática docente em espaço de sala de aula (educação formal) necessária à formação em Licenciatura, de modo a possibilitar o apostilamento ${ }^{1}$ dessa modalidade de formação no diploma do curso de Psicologia. Faz-se mister considerar que essa carga horária, atribuída a formação complementar, deve ser oferecida, obrigatoriamente, pelas Instituições de Ensino Superior - IES, que oferecem o curso de Psicologia, porém, seu estudo é facultado a formação do aluno de graduação, de acordo com seu interesse na Formação de Professores de Psicologia. Tal carga horária contempla modalidade especifica de Estágio Curricular Supervisionado (voltado para a Licenciatura) que difere das demais horas de formação em Estágios Supervisionados (básico e específico) da formação de Psicólogo mencionadas na referida resolução (BRASIL, 2011).

Os Estágios Supervisionados (básico e específico), que "deverão perfazer, ao todo, pelo menos, $15 \%$ (quinze por cento) da carga horária total do curso" de Graduação em Psicologia, contemplam a formação do Psicólogo, ou seja, versam sobre atividades de formação específicas que incluem o "desenvolvimento de práticas integrativas das competências e habilidades previstas no núcleo comum" (estágio supervisionado básico), e, o "desenvolvimento de práticas integrativas das competências, habilidades e conhecimentos que definem cada ênfase [de formação, que devem ser ofertadas em um mínimo de duas] proposta pelo projeto de curso" (estágio supervisionado específico) (BRASIL, 2011).

Essa nova DCN entrou em vigor quando publicada, porém, reconhecidas as dificuldades de sua operacionalização, foram oferecidos prazos para os cursos adaptarem seu funcionamento as suas proposições. Inicialmente, houve o estabelecimento de um prazo de dois anos para as matrizes das IES se adequarem, a partir da Resolução CNE/CES nº 2, de 1 de julho de 2015 (BRASIL, 2015), já publicada com quatro anos da DCN de 2011, porém que passou a regular todas as DCN para a formação inicial em nível superior (cursos de licenciatura, cursos de formação pedagógica para graduados e cursos de segunda licenciatura) e para a formação continuada.

Findado tal prazo no ano de 2017, ainda havia diversos cursos que não operacionalizaram

\footnotetext{
${ }^{1}$ Apostilamento é o registro feito no diploma (normalmente por meio de carimbo ou selo) que atesta que o aluno concluiu estudos adicionais. Esse é previsto na Lei Federal n.. 7044/82, e alterada pela LDB de 1996, e deve ser feito pela instituição de ensino que ofereceu o curso (BRASIL, 1982; 1996).
} 
as mudanças e consideraram a modalidade da Licenciatura para a formação em Psicologia. A Resolução CNE/CES no 3, de 3 de outubro de 2018, foi publicada com a finalidade de alterar o Art. 22 da Resolução CNE/CP n ${ }^{\circ} 2$, de $1^{\circ}$ de 2015, que estabelecia o prazo de dois anos para a adequação dos cursos à legislação da DCN para a formação de Licenciatura. A nova redação considerou que a adaptação do curso devesse se dar "no prazo improrrogável de 4 (quatro) anos", que passou a ser o novo limite considerado, e que determina a caracterização do presente estudo (BRASIL, 2018).

A presente pesquisa considerou o levantamento da realidade das instituições que oferecem a graduação em Psicologia no Brasil, quanto a proporem em suas matrizes curriculares as disciplinas que compõem a ênfase em Licenciatura em Psicologia, ofertada de modo compulsório pela IES, mas com o curso facultado pelo aluno. Considerou-se também a carga horária apresentada de modo a realizar uma análise comparativa quanto à adequação da formação oferecida na graduação em Bacharelado/Licenciatura de Psicologia. Tal se faz valer em função da sinalização, desde a LDB de 1996 (BRASIL, 1996), do ensino de Psicologia na educação fundamental e média.

\section{Metodologia}

A realização dessa pesquisa valeu-se do delineamento documental. O estudo apresentou caráter investigativo e exploratório, com a análise quantitativa, de corte transversal (GIL, 2002). Como já citado, levantaram-se as instituições de graduação em Psicologia têm, ou não, o curso de Licenciatura em Psicologia em sua matriz curricular.

A pesquisa documental buscou dados on-line, disponibilizados pelo e-MEC ${ }^{2}$, função disponível para acesso público no site do MEC. Consideraram-se os dados de todas as IES que possuem o curso de Psicologia como oferta de graduação, disponíveis no e-MEC. O único critério de escolha utilizado para a seleção das instituições foi a constatação de que a IES, cadastrada no e-MEC oferece o curso de Graduação em Psicologia.

O instrumento de coleta de dados contemplou uma planilha no software Microsoft Excel, onde foi tabulado, de forma sistematizada, os dados levantados a partir dos disponíveis sobre os cursos no site do e-MEC, complementados a partir de informação do site da IES, lá cadastrada.

\footnotetext{
${ }^{2} \mathrm{O}$ e-MEC é um sistema eletrônico de acompanhamento dos processos que regulam a educação superior no Brasil. O mesmo publicita os pedidos de credenciamento e recredenciamento de IES e de autorização de renovação e reconhecimento de cursos; além dos processos de aditamento, que são modificações de processos mais rápidos e eficientes, uma vez que são realizados eletronicamente. As instituições podem acompanhar (pelo sistema) o trâmite do processo junto ao MEC, o que, por sua vez, gera relatórios para subsidiar as decisões dos seus gestores (BRASIL, 2016).
} 
Buscaram-se as matrizes curriculares de cada curso. Para tal, recorreu-se à busca das mesmas, via internet, diretamente nos sites das IES que oferecem a formação em Psicologia.

Para os sites das IES que não disponibilizavam diretamente a matriz curricular do curso de Psicologia buscou-se a complementação desses dados a partir de outros meios de comunicação, considerada a solicitação formal para a pesquisa, quando necessário, por telefone e/ou e-mail. A coleta se deu entre os anos de 2015 e 2016, e foi atualizada no primeiro semestre do ano de 2018 .

Os dados foram discutidos a partir de análises descritivas em forma de textos, assim como gráficos (TRIOLA, 1999). Esses foram comparados com dados da legislação quanto a adequação as demandas dos objetivos da pesquisa.

\section{Resultados e discussão}

A partir da análise supracitada, obtiveram-se os seguintes resultados. No e-MEC estavam contabilizadas 543 IES $^{3}$ que oferecem a Graduação em Psicologia. Buscou-se contato com todas, de modo a se obter as respectivas matrizes curriculares (inicialmente, a partir da busca no site da instituição, e caso esse não disponibilizasse a matriz curricular, por meio de contato telefônico e/ou e-mail para o coordenador do curso). Dessas, que estão regularmente inscritas pelo site do e-MEC, foram acessadas as matrizes de 470 (86,56\%) instituições, que possuem curso de Graduação em Psicologia. Para as demais 73 (13,44\%), não se conseguiu os dados (a matriz não estava disponível no site da instituição; não se encontrou o site da IES; a IES não dispõe de site eletrônico; o endereço eletrônico disponível no e-MEC apresentava erro; os coordenadores/gestores/responsáveis não responderam a até três tentativas de contato por e-mail e/ou telefone, ou essas formas de contato apresentavam-se equivocadas/haviam sido alteradas).

Ao fazer o levantamento dos dados disponibilizados (470 matrizes), verificou-se que 425 (90,43\% do total analisado, ou 78,27\% das 543 matrizes) instituições com graduação em

\footnotetext{
${ }^{3}$ Foram consideradas apenas as matrizes mais atuais, de cada curso nos casos em que o curso apresentava mais de uma matriz (ou matrizes de adaptação ou de transição) conforme previsto na legislação pertinente. Por outro lado, cursos que apresentavam mais de uma matriz curricular, em função de diferenças quanto a oferta de disciplinas/cargas horárias para a oferta do curso matutino, vespertino, integral ou noturno, foram analisadas se tais apresentavam diferenças quanto a oferta de disciplinas. Aquelas que se mostraram com as mesmas disciplinas, com variações de oferta por semestre (por exemplo, graduação matutina realizada em cinco anos e noturna em cinco anos e meio ou seis anos), foram consideradas como equivalentes e contabilizadas como uma para a análise da pesquisa. Já as que apresentavam uma ou mais diferenças quanto a disciplinas ou carga horária (desconsideradas as disciplinas optativas ou seminários de temas atuais ou seus equivalentes) foram contabilizadas como duas matrizes para o mesmo curso.

Análise similar foi considerada quanto uma mesma IES oferecia o curso e mais de um campus. Aquelas em que havia equivalência de matrizes, independente do número de ofertas de curso/campi, foram contabilizadas apenas uma vez. Já as que apresentavam diferenças quanto as matrizes por campus, tiveram cada matriz distinta analisada.
} 
Psicologia não apresentavam a modalidade/ênfase da Licenciatura em sua matriz curricular, seja como componente regular; como ênfase de formação; ou como complementação a formação (atualização, obtenção de novo título, ou qualquer outra forma de composição de formação). As que ofertavam em sua matriz a ênfase, ou modalidade complementar, de Licenciatura são 45 instituições, totalizando assim 9,57\% (ou 8,29\% das 543 matrizes) de todas as instituições que oferecem a graduação em Psicologia em todo o Brasil (conforme se verifica no Gráfico 1).

Gráfico 1: Distribuição das IES que oferecem o curso de graduação em Psicologia e ofertam Licenciatura desse no Brasil

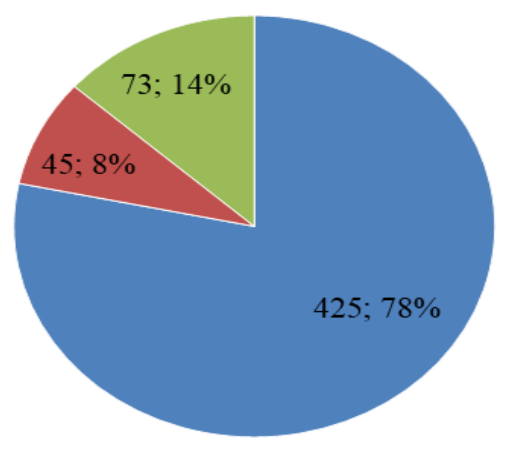

$$
\begin{aligned}
& \text { • IES's que não ofertam Licenciatura } \quad \text { IES's que ofertam Licenciatura } \\
& \text { —IES's que não responderam à pesquisa }
\end{aligned}
$$

Fonte: elaborado para a pesquisa.

Entende-se que tal número é ainda pequeno ao se analisar a discussão aqui proposta. As alterações na legislação contemplam caráter de normativas não facultativas, assim, deveriam ter sido cumpridas. Mesmo ao se considerar as dificuldades quanto a proposição de alterações nas matrizes curriculares, verifica-se, no texto acima, que houve prazo, mais do que suficiente para que as IES realizassem tais ajustes.

Pode-se considerar a DCN de 2004 como o marco inicial para essas mudanças, ou as legislações complementares do estado de São Paulo, e demais marcos gerais das DCNs, em geral, até 2011. Não obstante, reconhece-se que os mesmos não apresentavam os caminhos para operacionalizar as alterações. Essa justificativa não pode ser acolhida a partir de 2011, visto que a nova DCN dos cursos de graduação em Psicologia figura, explicitamente, como deve ser a reorganização da matriz para a apresentação da Licenciatura em Psicologia. Tal entrou em vigor quando de sua publicação. Ainda assim, por mais duas vezes, a Resolução do CNE/CES n5/2011 é ainda complementada, após quatro anos, com prorrogação do prazo de efetivação de tais ajustes. Inicialmente pela Resolução CNE/CES nº 2/2015 que estabelece informações 
complementares para a regulamentação dos cursos de licenciatura, e determina um prazo de dois anos para que as IES realizem os ajustes a mesma. E sequencialmente, pela Resolução CNE/CES no 3/2018 que alterou o texto da Resolução CNE/CES nº 2/2015 para o prazo de quatro anos, ou seja, a findar-se em julho de 2019 (BRASIL, 2004; 2011; 2015; 2018).

Entende-se ainda, como consideração, o fato de que a Licenciatura em Psicologia deve ser ofertada de forma compulsória pela IES, sendo facultado ao aluno seu curso. Ora, tal informação pode ser lida a partir de diferentes prismas. Por um lado, pode não ser de interesse para a IES a estruturação da Licenciatura em Psicologia, visto que, não necessariamente haverá alunos para cursá-la. Assim o investimento (econômico, de tempo, e, de demais recursos) pode parecer um desperdício que não trará retorno (econômico ou social) visto que pode não ter alunos. Quanto a esse argumento, retoma-se a legislação que contempla que tal oferta não é facultativa, mas obrigatória para a IES, e assim a que ainda não a realizou peca e poder sofrer sanções quando de avaliações futuras do curso (BRASIL, 2011).

Por outro lado, para a maior parte das $\mathrm{IES}^{4}$, o investimento na adequação da matriz do curso de Psicologia de modo a oferecer a ênfase, ou formação complementar, em Licenciatura não deve ser muito maior do que o recurso designado aos especialistas que fizerem a adequação formal do texto complementar ou matriz, contemplando seu correspondente no Projeto Pedagógico do Curso - PPC ou Projeto Político Pedagógico - PPP da IES. Isso porque se entende que para a implementação da Licenciatura em Psicologia, a maior parte das IES já dispõe dos recursos necessários como sala de aula, biblioteca (com acervo específico), laboratório de informática, material de multimídia, assim como os recursos humanos (professores com formação específica), e parcerias com instituições de ensino (escolas) para a efetivação dos Estágios Curriculares Supervisionados como a prática docente em espaço de educação formal. Ou seja, não há muito que ser construído para a efetivação da Formação de Professores de Psicologia que a IES já não disponha como recurso para a oferta de qualquer curso de formação pedagógica (Pedagogia, Normal Superior, ou todas as licenciaturas nas demais áreas específicas).

Por fim, pode-se pensar sobre o interesse dos alunos, que cursam Psicologia, em buscar a formação em Licenciatura. Há investimento a ser realizado, pessoal, a partir dos interesses de cada um, e econômico, considerado os recursos para continuar a estudar (deslocamento, materiais, alimentação, etc.) que podem concorrer com seu ingresso no mercado de trabalho, por exemplo, atrasando-o. Não obstante, todo conhecimento adquirido pode ser utilizado em sua

\footnotetext{
${ }^{4}$ O que é uma consideração informal, visto que não se analisou formalmente a oferta de cursos de cada uma.
} 
prática como Psicólogo, nas mais diversas áreas de atuação, ou com as mais distintas correntes teóricas que o neófito escolher trabalhar. Além disso, a Licenciatura abre-se como possibilidade de formação complementar que acresce ao arcabouço daquele que optar por investir nessa formação, o que pode ser reconhecido como interesse para muitos alunos em curso, e mais ainda para egressos da graduação que, por exemplo, em função de suas experiências no mercado de trabalho, podem desejar retornar ao assento institucional para complementar sua formação. Qualquer que seja a motivação do aluno é sempre de interesse para a IES a sua matrícula.

Apesar de não figurar na metodologia proposta para a pesquisa, informalmente, visto que não se atentou as minúcias de todas as matrizes, verificou-se que em algumas das matrizes de transição (que ocorriam em paralelo as mais atuais, aguardando a finalização do fluxo de alunos que naquelas ingressaram) algumas instituições se contrapunham a legislação. Tais, apresentavam matrizes que, inicialmente, previa a modalidade da Licenciatura em Psicologia, porém, que não as mantinha em suas atualizações. Tal análise leva ao questionamento sobre o porquê dessa escolha de gestão, que se contrapõe a legislação, assim como sobre o porquê de tal proposta de extinção da oferta da Licenciatura.

Faz-se necessário que ocorram novas propostas de acordo com as demandas das diretrizes, pois, além de contribuir de forma significativa para sociedade na formação dos jovens adultos, também contribui no campo de atuação da Psicologia. Nesse sentido, fica a questão de quais serão os reais motivos, para além da má vontade dos gestores, quanto ao impedimento dos ajustes da matriz do curso de Psicologia de modo a contemplar a Licenciatura em Psicologia.

\title{
Considerações Finais
}

Assunção (1999), ao refletir sobre a relação dos graduandos de Psicologia com a Licenciatura, considera-se que:

\begin{abstract}
De modo geral, a questão da docência (Licenciatura) não é tratada no decorrer do Curso, até mesmo porque as matérias relacionadas à Educação, além de serem em um número reduzido no currículo, em sua maioria são de caráter optativo. Além disso, essas disciplinas enfocam, de acordo com o depoimento dos (as) alunos (as), a Psicologia Escolar e não à docência em Psicologia, e são, ainda tratadas como disciplinas de menor importância (ASSUNÇÃO, 1999, p. 52).
\end{abstract}

Percebe-se que não há de fato uma discussão sobre o que é a Licenciatura, e suas diferenças da Psicologia Escolar/Educacional, para com os graduandos. Informalmente, a partir da experiência de docência em Psicologia (dos autores e de pares) indica que há apenas uma concessão das intuições em oferecer ou não a ênfase durante a graduação. Isso leva a questionar 
do posicionamento dos acadêmicos frente a um obstáculo que já estorva a efetivação da legislação há alguns anos.

Ao analisar os dados coletados, verificou-se que existe incoerência quanto à organização das IES no Brasil. Por exemplo, ao se reconhecer que apenas 45, que representam 9,57\% das 470 analisadas, ou 8,29\% das 543 IES investigadas em todo território brasileiro, que ofereciam o curso de graduação em Psicologia, dispõem, em suas matrizes curriculares obrigatórias, a ênfase/modalidade regular de Licenciatura em Psicologia em sua estrutura curricular, de modo a atender a legislação vigente questiona-se o por quê de tal demanda (obrigatória) não tem sido atendida.

Nesse sentido, promove-se a reflexão sobre o que vem sendo constituído, pelas IES que oferecem o curso, em termos da oferta da Licenciatura para os acadêmicos de Psicologia. Há diversas questões que ficam em aberto, e que devem ser discutidas em novos estudos, por exemplo: 'São ofertas de formação sérias?'; 'Essas IES se preocupam com a qualidade da formação dos acadêmicos?'; 'As IES oferecem o que há de melhor/mais atual do conhecimento e formação em psicologia para seus estudantes?'. Por outro lado, pode-se também inquirir a partir de uma perspectiva menos favorável em relação as IES, por exemplo: 'As IES ofertam cursos limitantes?'; 'Os cursos de formação se voltam para demandas econômicas de mercado? Ou para a melhor capacitação profissional?'; 'Por que as IES não atendem a legislação deliberativa sobre a oferta de Licenciatura para os cursos de formação em Psicologia?’. Cabem ainda as perguntas do tipo: 'Até quando tal descaso será mantido?'; ou, 'O que falta para que os ajustes sejam efetivados?'

Popularmente é sabido que em havendo a oferta, haverá a procura. Tal pode ser pensada a partir do olhar da realização da modalidade de Licenciatura de Psicologia por parte do aluno, ou, a partir do prisma da atuação no mercado de trabalho para aquele que dispõe de tal formação. $\mathrm{O}$ mercado de trabalho atual demanda um profissional que seja capaz de assumir perspectiva empreendedora. Assim, estima-se que maior e melhor formação oferecerá diferencial para aqueles que a detém no sentido de se inserirem no mercado já existente, ou, por outra via, aquele que detém formação complementar poderá ser capaz de criar demandas para a aplicação desses conhecimentos.

Além dessas possibilidades, como previsto na DCN de 2011 (BRASIL, 2011) a Formação de Professores de Psicologia abre espaço para a atuação do licenciado no ensino fundamental (e nos diversos níveis e modalidades de formação) (PEREIRA, 2019). Isso porque reconhece a necessidade de renovação dos processos ensino-aprendizagem, que por sua vez atende a 
necessidade dos alunos que estão no ensino (nos diversos níveis e modalidades de aprendizagem).

Diante esse cenário, faz-se necessária uma renovação no âmbito da formação em Psicologia. Em especial, no que diz respeito à fiscalização e comprometimento das gestões acerca do direito dos próprios alunos e sociedade, como um todo, reconhecer as possibilidades que a Psicologia, como disciplina fundamental, oferece para o desenvolvimento de seus alunos. Acredita-se que sua oferta instigue alunos a adquirir uma visão reflexiva do mundo e do próprio ser humano.

No que concerne à legislação, estas cumprem seu papel em suas determinações. Como se pode observar, as mesmas evoluem e se adequam as demandas da sociedade, por exemplo, ao reconhecer que é necessário tempo de adaptações para as IES efetivá-las. Tal é reconhecido ao se verificar que as mudanças na legislação prorrogou, por várias vezes, esse prazo para adequação. Cabe, no entanto, às autoridades competentes se atentarem para realidade constada no presente trabalho e tomar as medidas cabíveis.

\section{Referências}

ASSUNÇÃO, M. M. S. Curso de Psicologia: Algumas Reflexões sobre o Bacharelado e a Licenciatura. Educação em Revista, v. 29, p. 45-60, 1999.

BOCK, A. M. B.; FURTADO, O.; TEIXEIRA, M. L. T. Psicologias: uma introdução ao estudo de psicologia. 13. ed. São Paulo: Saraiva, 2001.

BRASIL. Lei $n^{0} 4.119$ de 27 de agosto de 1962. Dispõe sobre os cursos de formação em psicologia e regulamenta a profissão de psicólogo. Brasília (DF): Diário Oficial da União p. 9253, 1962.

BRASIL. Ministério de Educação e Cultura. Lei $\mathbf{n}^{\mathbf{0}} \mathbf{7 . 0 4 4}$, de 18 de Outubro de 1982. Altera dispositivos da Lei ${ }^{\circ} 5.692$, de 11 de agosto de 1971, referentes a profissionalização do ensino de $2^{\circ}$ grau. Brasília: MEC, 1982.

BRASIL. Ministério de Educação e Cultura. LDB - Lei no 9394/96, de 20 de dezembro de 1996. Estabelece as diretrizes e bases da Educação Nacional. Brasília: MEC, 1996.

BRASIL, Ministério da Educação, Conselho Nacional de Educação \& Câmara de Educação Superior. Parecer CNE/CES no 776/1997, aprovado em 3 de dezembro de 1997 - Orientação para as diretrizes curriculares dos Cursos de Graduação. Brasília, DF: CNE/CES, 1997a.

BRASIL. Secretaria de Educação Fundamental. Parâmetros curriculares nacionais: introdução aos parâmetros curriculares nacionais / Secretaria de Educação Fundamental. Brasília: MEC/SEF, 1997b. 
BRASIL, Ministério da Educação, Conselho Nacional de Educação \& Câmara de Educação Superior. Resolução CNE/CES n⿳ 8, de 7 de maio de 2004. Institui as Diretrizes Curriculares Nacionais para os cursos de graduação em Psicologia. Brasília, DF: CNE/CES, 2004.

BRASIL, Ministério da Educação, Conselho Nacional de Educação \& Câmara de Educação Superior. Parecer CNE/CES N. ${ }^{\circ}$ 338, de 12 de novembro de 2009. Aprecia a Indicação CNE/CES n $n^{\circ}$ 2/2007, que propõe a alteração do art. 13 da Resolução CNE/CES n ${ }^{\circ} 8$, de 7 de maio de 2004, que institui as Diretrizes Curriculares Nacionais para os cursos de graduação em Psicologia. Brasília, DF: CNE/CES, 2009.

BRASIL, Ministério da Educação, Conselho Nacional de Educação \& Câmara de Educação Superior. Resolução CNE/CES no 5, de 15 de março de 2011. Institui as Diretrizes Curriculares Nacionais para os cursos de graduação em Psicologia, estabelecendo normas para o projeto pedagógico complementar para a Formação de Professores de Psicologia. Brasília, DF: CNE/CES, 2011.

BRASIL, Ministério da Educação, Conselho Nacional de Educação \& Câmara de Educação Superior. Resolução CNE/CES no 2 , de $1^{\circ}$ de julho de 2015. Define as Diretrizes Curriculares Nacionais para a formação inicial em nível superior (cursos de licenciatura, cursos de formação pedagógica para graduados e cursos de segunda licenciatura) e para a formação continuada. Brasília, DF: CNE/CES, 2015.

BRASIL, Ministério da Educação. Cadastro Nacional de Cursos e Instituições de Educação Superior Cadastro e-MEC. 2016. Sistema e-MEC. Disponível em: http://emec.mec.gov.br/. Acesso em: 10 abr. 2016.

BRASIL, Ministério da Educação, Conselho Nacional de Educação \& Câmara de Educação Superior. Resolução CNE/CES no 3, de 3 de outubro de 2018. Altera o Art. 22 da Resolução $\mathrm{CNE} / \mathrm{CP} \mathrm{n}^{\circ} 2$, de $1^{\circ}$ de 2015, que define as Diretrizes Curriculares Nacionais para a formação inicial em nível superior (cursos de licenciatura, cursos de formação pedagógica para graduados e cursos de segunda licenciatura) e para a formação continuada. Brasília, DF: CNE/CES, 2018.

COMITÊ NACIONAL DE EDUCAÇÃO EM DIREITOS HUMANOS - CNEDH. Plano Nacional de Educação em Direitos Humanos. Ministério dos Direitos Humanos. Brasília, 2018 .

CONSELHO FEDERAL DE PSICOLOGIA (CFP); CONSELHOS REGIONAIS DE PSICOLOGIA. Ofício n⿳0 0633-08/DIR-CFP. Brasília: CFP, 2008.

FERNANDÉZ, A. A Inteligência Aprisionada. Porto Alegre: Artes Médicas, 1991.

FINELLI, Docência em Avaliação Psicológica: A formação em Minas Gerais - Brasil. Revista Galego-Portuguesa de Psicoloxía e Educación, v. 21, n. 2, 49-59, 2013.

FINELli, L. A. C.; FREITAS, S. R.; CAVALCANTI, R. L. Docência em Avaliação Psicológica: a formação no Brasil. Revista de Estudios e Investigación en Psicología y Educación, v. Extr., n. 12, p. 12-30, 2015.

GADOTTI, M. Concepção dialética da educação. São Paulo: Cortez, 1983. 
GIL, A. C. Como elaborar projetos de pesquisa. 4. ed. São Paulo: Atlas, 2002.

GUIMARÃES, P. A utilidade da educação de adultos: a aprendizagem ao longo da vida na União Europeia e a política pública de educação e formação de adultos em Portugal. Laplage em Revista, v. 2, n. 1, p. 36-50, 2016.

JACÓ-VILELA, A. M.; ESPÍRITO SANTO, A. A.; DEGANI-CARNEIRO, F.; GOES, L. O.; VASCONCELLOS, M. A. G. N. T. Investigando em História da Psicologia: contribuições metodológicas. Interacciones: Revista de Avances en Psicología, v. 2, n. 2, p. 123-134, 2016.

LEITE, S. A. S. Psicologia no Ensino Médio: desafios e perspectivas. Temas em Psicologia, v. 15, n. 1, p. 11-21, 2007.

MACHADO, L. A.; VITÓRIA, M. I. C. O ensino de psicologia no currículo da educação básica: análise da formação docente. Revista Educação Online, Rio de Janeiro, v. 13, n. 27, p. 189-216, jan./abr. 2018.

MELlO, M. A Psicologia no Ensino Médio: uma análise sobre a prática docente. Psicol. Ensino \& Form., Brasília, v. 4, n. 2, p. 65-80, 2013.

MITRE, S. M.; SIQUEIRA-BATISTA, R.; GIRARDI-DE-MENDONÇA, J. M.; MORAISPINTO, N. M.; MEIRELLES, C. A. B.; PINTO-PORTO, C.; MOREIRA, T.; HOFFMANN, L. M. A. Metodologias ativas de ensino-aprendizagem na formação profissional em saúde: debates atuais. Ciênc. Saúde Coletiva, Rio de Janeiro, v. 13, supl. 2, p. 2133-2144, dez. 2008.

OLIVEIRA, H. K. T.; RODRIGUES, M. M. M.; SIQUEIRA, P.; LOPES, R. M. L.; BUOSI, L. M. Contribuições da psicologia para a inclusão da pessoa surda no ensino fundamental. 2018. 27 f. Trabalho de Conclusão de Curso (Graduação em Psicologia) - Centro Universitário de Várzea Grande - UNIVAG, Várzea Grande, MT, 2018.

PEREIRA, O. C. N. O licenciado em Psicologia no ensino fundamental: possibilidade de atuação. Psicol. Esc. Educ., Maringá, v. 23, e178679, 2019.

ROSA, C. L. Educação profissional, científica e tecnológica, formação humana e a psicologia escolar e educacional. 2018. 183 f. Dissertação (Mestrado em Educação) Universidade do Extremo Sul Catarinense - UNESC, Criciúma, SC, 2018.

SCHULTZ, D. P.; SCHULTZ, S. E. História da psicologia moderna. São Paulo: Cultrix, 2005.

SILVA JÚNIOR, A., CATARINI, M.; PRUDENTE, R.C.A.C. 1945-1962: Os antecedentes da regulamentação da psicologia como profissão no Brasil. CES Revista, v. 18, n. 1, p. 157-167, 2006.

TRIOLA, M. F. Introdução à estatística. 8. ed. Rio de Janeiro: LTC, 1999. 